\title{
The mutation rate to Huntington's chorea
}

\author{
MICHAEL SHAW*‡ AND ADRIAN CARO $\dagger$ \\ From *the Department of Biology, University of East Anglia, Norwich, Norfolk NR4 7TJ, and $\dagger$ Theatre Royal \\ Surgery, Theatre Street, Dereham, Norfolk NR19 2EN
}

SUMmARY The problems of estimating the mutation rate to Huntington's chorea, or the proportion of new mutants among all sufferers, are discussed. The available survey data are reviewed. The prevalence of sporadic phenotypes, which include new mutations, is probably less than $2 \cdot 5 \%$. New mutants probably make up around $0 \cdot 1 \%$ or less of all sufferers.

The purpose of this review is to establish that genuinely sporadic cases of true, heritable, Huntington's chorea are extremely rare. The diagnosis of the disease can cause immeasurable distress and hardship to both the sufferers and their relatives and offspring. For example:

A young man had the consequences of Huntington's chorea explained to him following the diagnosis being made in his father. This young man broke off his relationship with his intended wife, stopped all attempts to further himself at work, and made no plans for the future. He became deeply depressed. He refused to have anything to do with anybody who might have helped him. The diagnosis made in his father was made in error and his father actually got better. This man refused to change his belief about the diagnosis in his father and its consequences and also refused to change his now depressed life-style. He would not discuss this with anybody and is very obviously a likely candidate for suicide. This man's life has probably been ruined for ever by the label 'Huntington's chorea' being applied to his father. Although of course the suffering in the patient would have occurred even if the diagnosis had been applied correctly, it was in this case completely needless.

Recently, as many as one in five of those diagnosed as suffering from Huntington's chorea at certain clinics has had no known family history (Carter, personal communication, 1976). Diagnosis of such a grave inherited disorder without reasonable demonstration of its heritable nature in each case is hard to justify. That it has so often been justified seems to $\ddagger$ Present address: Department of Biology, University of York, Heslington, Yorks YO1 5DD.

Received for publication 7 September 1981. reflect a widespread belief that the symptomatology never appears unless a mutant gene is present, and that the mutation rate is extremely high. We wish, in this review, to collect together all the data we have been able to find that bear on these beliefs. We shall contend that, at the most, fewer than one patient out of a hundred can be expected to be a new mutant. In view of this, we believe that when no family history can be established for a patient otherwise seemingly typical, a label that is less socially catastrophic than 'Huntington's chorea' should be attached to the patient's disease. Lyon ${ }^{1}$ suggested 'non-hereditary chronic adult chorea', but any name for the condition that does not imply a hereditary nature would do. 'Chronic adult chorea' is simple and adequate.

\section{Phenotype and genotype}

In any serious heritable disease the frequently obscured distinction between phenotype and genotype is extremely important, because a single phenotype may have diverse causes. For example, teratogenic drugs can cause morphological abnormalities indistinguishable from those produced by mutant alleles at certain loci. There may also be dominant and recessive alleles at various loci, all capable of causing a particular phenotype. So far, admittedly, only a dominant genetic factor is known to produce Huntington's chorea, but until the underlying lesions are identified and understood, it is hardly possible to rule out other causes. Thus, no matter how distinctive the phenotype of a patient, their genotype can, at present, only be established through study of the inheritance of that phenotype. Since laymen, insurance assessors, and others, undoubtedly interpret the diagnosis 'Huntington's 
chorea' as a genotype we believe the medical profession should also so limit itself.

Thus, when discussing sporadic cases we must ask two questions. Firstly, of patients who show the classic symptoms of Huntington's chorea how many in fact carry the mutant gene? Secondly, of those patients who carry the gene (as confirmed subsequently or at the time of the diagnosis by family history) how many are new mutants? This makes apparent that the absolute mutation rate is of little importance medically. What matters is the rate of mutation relative to the prevalence of the disease. Unfortunately, neither figure is easy to estimate, and the data to provide a reasonably precise point estimate do not exist at present. The next section discusses why this is so.

\section{Methodological problems}

\section{FAMILY HISTORIES}

It is more difficult than commonly realised to obtain an adequate family history. Ideally, the search should be carried out by an experienced and medically trained social worker with specialist genealogical training. Tact and experience in dealing with the relatives of those suffering from distressing neurological disorders is clearly essential, but it is also desirable that the worker should be allowed to check hospital and other records, which is not possible without medical training. The need for genealogical training is obvious but family tracing is also surprisingly expensive; in the UK it costs, for example, $£ 6.00$ for every death or birth certificate obtained. Travelling expenses may also be considerable. If less thorough methods of searching are used, a positive family history can easily be missed. For example, several times during the survey reported in Caro, ${ }^{2}$ relatives strenuously denied any knowledge of hereditary madness in the family. While death certificates corroborated this, making no mention of Huntington's chorea, examination of the hospital notes made it quite clear that some of the patients concerned were, in fact, sufferers. Reports from relatives are particularly unreliable, partly because of imperfect memories and partly because of conscious or unconscious denial of the disease in the family. The last is understandable enough and has often been commented on in the literature on Huntington's chorea. ${ }^{2}$ At the start of Caro's survey, ${ }^{2}$ eight patients out of 50 were reported as coming from families with no known history. In no case was this found to be true on detailed search.

\section{LEGITIMACY}

As Huntington's chorea is frequently manifested only late in life, it is often impossible to check that the natural parents of the sufferer are actually the genetic parents, because one or both may be dead. Even if the parents are alive, it may not be easy to check paternity without causing offence or running the risk of causing great distress. Thus it is very often impossible to exclude illegitimacy when an apparently new mutation has been found. It is worth noting here the experience of Wendt and Drohm. ${ }^{3}$ Of 4000 patients considered, they found one case, with choreic offspring, both of whose parents were living at advanced ages. Blood grouping, however, revealed that this patient, their only likely mutation, was undoubtedly illegitimate.

\section{EARLY DEATH}

Judged from segregation ratios, the penetrance of the gene causing Huntington's chorea is very high. ${ }^{4}$ Nevertheless, late manifestation is quite frequent. Wallace $^{5}$ details the age-specific incidence rates found in the accumulated Queensland data. A more extensive series is to be found in Wendt and Drohm. ${ }^{3}$ From these, a cumulative probability distribution for the age at onset can be constructed (fig 1). Most workers have reported similar mean ages at onset with similar spreads, so this distribution should apply at least roughly to other populations. Now, suppose a person has developed the disease, but that both his parents died in good neurological health, moderately, but not especially, young, say at 64

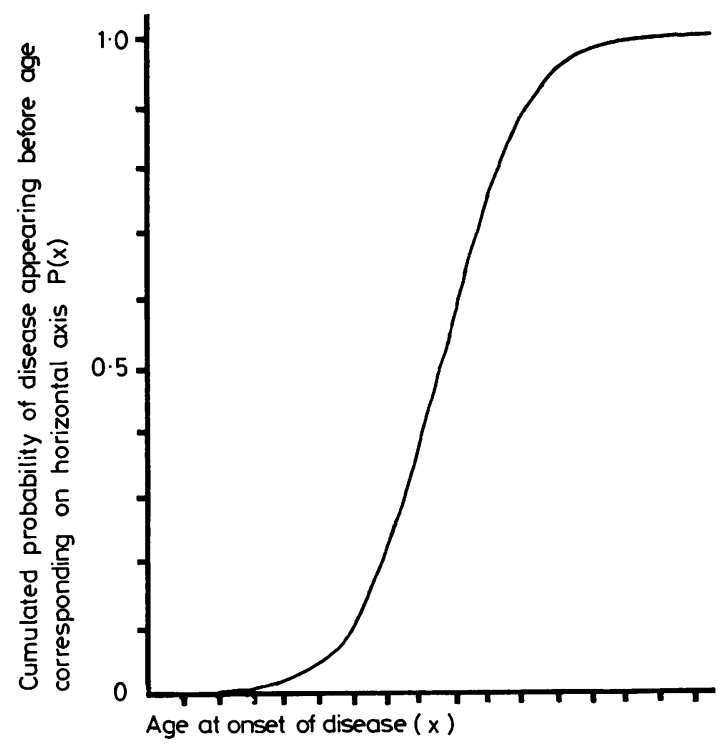

FIG 1 Plot of $P(x)$, cumulative probability of age at onset. Probability of two subjects, one of whom is choreic, not manifesting the disease before ages $x$ and $y$, respectively, is $1-\frac{1}{2}[P(x)+P(y)]$. 
(father) and 62 (mother). Then the probability that, given that one or other was a carrier, both would die healthy is $7 \%$, a fairly substantial figure. So it is not implausible to suppose that one of them did carry the gene. Evidently, to be sure that the disease was not inherited, all relatives-sibs, uncles, aunts, parents, and grandparents-must have had clean bills of neurological health to advanced ages in the majority of cases.

\section{BIAS}

All the above factors, and others, can cause bias in the ascertainment of sporadic cases and bias in determining their genetic nature. Firstly, there is bias against the demonstration of sporadic cases. By definition such cases cannot be found by family searching, so that one efficient method of ascertainment cannot be used. Also, to prove a sporadic case we require good evidence that Huntington's chorea has not previously occurred in the family, together with proof of legitimacy and reliable diagnosis. Finally, to prove a new mutation, it is essential to have evidence that the disease is inherited, through the diagnosis of affected offspring. This is only likely to be possible retrospectively.

On the other hand, a person with worrying neurological symptoms, but no inkling that they might have an incurable inherited disorder, may be more likely to seek medical advice than a member of an afflicted family. Since family histories are usually sought only when a diagnosis of Huntington's chorea seems likely on other grounds, these patients may be as likely to enter a survey as any other proband.

Lastly, there is diagnostic bias. The elimination of this depends largely on the professional standards of the research worker. In particular it is important that in a survey as many patients as possible, and all case notes, are examined by a specialist in the disease. Stevens, ${ }^{6}$ for example, reported $29 \%$ misdiagnosis in the cases initially referred as probands in his extensive survey around Leeds in the UK. Similarly, Hayden $e t$ al $^{7}$ quote an initial misdiagnosis rate of $40 \%$.

\section{Methods of estimating the mutation rate}

\section{DIRECT ENUMERATION}

An obvious method of finding the proportion of sporadic cases and new mutations among the affected population (from which it is only a small step to calculate the absolute mutation rate) is to count all sufferers on a particular day, noting whether they inherited the disease or not, and whether they have passed it on to their offspring. There are great problems in putting into practice this ideal scheme. Firstly, it is very hard to ascertain Huntington's chorea completely in a defined population, or even to estimate the degree of underascertainment that has occurred. When ascertainment is incomplete, the problems of bias mentioned in the previous section necessarily arise. Secondly, as discussed above, deciding if a case is genuinely sporadic is far from easy. Finally, the determination of the mutants among the sporadic cases can only be done retrospectively by observing their offspring. (Obviously, we feel that the clinical title given to the sporadic cases should not be Huntington's chorea until the inheritance is proven.) Unfortunately, a fully retrospective study cannot be easily undertaken, because many familial cases are only recognised after they have occurred, through study of the offspring. A similar increase in the efficiency of detection of sporadic cases retrospectively will not take place. Furthermore, in a retrospective study there is no opportunity to check the accuracy of diagnoses, an important factor if the study extends more than a few years back from the present day.

\section{INDIRECT ESTIMATION}

It might seem from the foregoing discussion that direct enumeration of sporadic cases and mutations is not the best way of determining their frequency. An alternative method, first suggested by Haldane, ${ }^{8}$ is superficially attractive, but in practice turns out to have just as many difficulties. The method assumes that the population under study is in genetic equilibrium between steady selection against an unfavourable allele and mutation of the normal allele to it. A simple mathematical expression relates the mutation rate, the prevalence of the mutant allele in the population, and the selective difference between the two forms. Some care is needed in defining these qualities but, if the selection and prevalence are known and the assumption of equilibrium is admitted, the mutation rate can be calculated. (See Charlesworth and Charlesworth ${ }^{9}$ for details.)

The method has been used with success for some other genetic diseases in man. ${ }^{10}$ In the case of Huntington's chorea, it seems very unlikely that selection against the mutant allele has been constant for long enough to allow equilibrium to be approached closely..$^{11-13}$ Selection is mostly social in form, operating through reduced marriage rates, increased fecundity, social ostracism, etc. It is unlikely to be constant in every generation of a lineage, and the whole pattern of selection is likely to change as societies change. At best, fitness can only be measured in 20th century societies. It seems unreasonable to expect selection in, say, Tudor Britain to conform to the same pattern: but if selection is relatively weak (of the order of $10 \%$ difference 
TABLE 1 Estimates of fitness, prevalence, and mutation rate

\begin{tabular}{|c|c|c|c|c|c|}
\hline Authors & Region & Date & Fitness & Prevalence per million & Mutation rate \\
\hline Kishimoto et al ${ }^{14}$ & Aichi Province, Japan & $1956(?)$ & 0.65 & $3 \cdot 8$ & $0.7 \times 10^{-6}$ ind irect \\
\hline Marx ${ }^{15}$ and Pearson et al ${ }^{16}$ & Minnesota USA & 1955 & $1 \cdot 16$ & $54 \cdot 0$ & - \\
\hline Reed and Neel11 & Michigan, USA & 1940 & 0.85 & $40 \cdot 0$ & $\int 5 \times 10^{-6}$ direct \\
\hline Panse17 & Germany & (?) & $1 \cdot 18$ & $32 \cdot 0$ & $=$ \\
\hline Shokeir ${ }^{18}$ & Canada & 1974 & $1 \cdot 18$ & $84 \cdot 0$ & - \\
\hline Mattsson 19 & Sweden & 1965 & 0.97 & 47.0 & $5 \times 10^{-6}$ direct \\
\hline Wendt and Drohm ${ }^{3}$ & Germany & 1950 & 0.95 & $22 \cdot 0$ & $1.5 \times 10^{-6}$ indirect \\
\hline
\end{tabular}

between the genotypes) then about 20 generations are required before the population will be near the equilibrium. Also, the weaker the force of selection the more sensitive the estimate of mutation rate becomes to errors in the estimate of selection. Surveys concur in finding that the genetic fitness of sufferers from Huntington's chorea is not very different from the rest of the population (table 1). However, a potential advantage of the method is that it is relatively insensitive to small errors in the prevalence rate, and therefore to small numbers of sporadic cases, resulting from non-genetic causes, misdiagnosis, etc.

Bearing these points in mind, table 1 shows the estimates of the fitness of sufferers that we have been able to find. Where the fitness of the mutant genotype is greater than that of the normal genotype, genetic theory implies a continuing increase in its frequency and the data can shed no light on the mutation rate, which may be arbitrarily small. None of the several papers in which estimates of the mutation rate were made considered that their figures merited much consideration. Reed and Neel's estimate $^{11}$ (note a correction in Charlesworth and Charlesworth $^{9}$ ) is quite high. Those of Kishimoto et $a^{14}$ and Mattsson ${ }^{19}$ are among the lowest human mutation rates ever postulated. In no case has the society been sufficiently static to justify the minimal necessary assumption of constant selection over the last eight to 20 generations (say, 200 to 500 years). Furthermore, the estimates of fitness are very inaccurate. Their formal confidence limits would more or less coincide with the range of possible values. For example, if Wendt and Drohm's ${ }^{3}$ figure for fitness were 0.98 instead of 0.95 their estimate of mutation rate would more than halve.

\section{Observed cases of mutation}

At this point we would like to reiterate that bias in surveys towards or away from familial cases, if it exists, is very likely to be reflected also in clinical practice. However, a very conservative estimate of the rate at which sporadic cases will appear in clinical work can be obtained by comparing the number of cases seen with the total number of families in the survey, rather than the total number of cases. This estimate is an extreme upper bound; it would reflect clinical reality only if families in surveys were always represented by a single member known to the medical profession. This is not the case. As stated above, a more plausible estimate is that obtained by comparing the number of sporadic cases seen with the total number. Table 2 lists those reports, whether or not they are based on survey data, that reported suspected mutants. It is immediately clear that published reports of sporadic cases are rare; in Bell's data, for example, only three of 190 families trace to an apparently sporadic case. ${ }^{20}$ Most of the family trees span three to five generations. In Hayden's study, ${ }^{7} 80 \%$ of present sufferers could be connected in a single lineage. Evidently, if sporadic cases are common, they rarely leave offspring. It seems simpler to believe that they are rare.

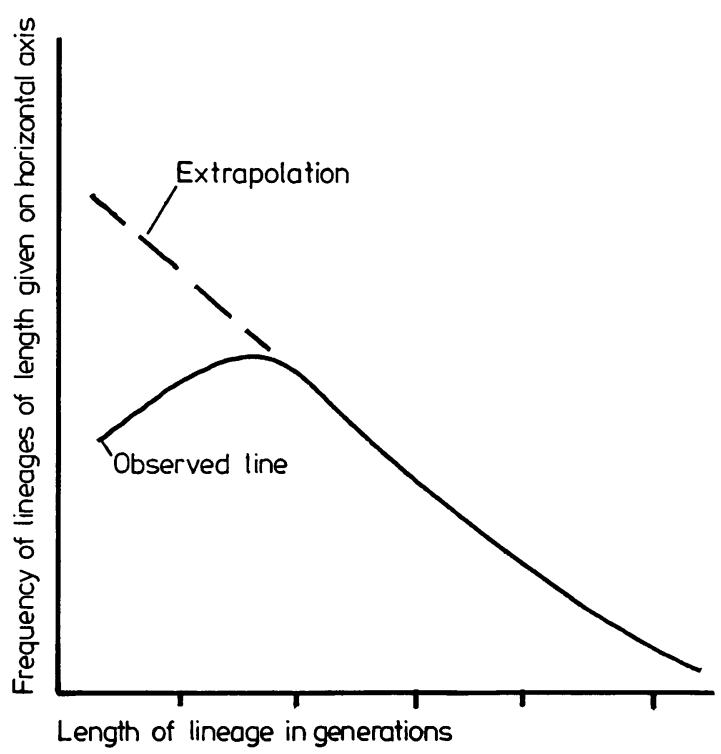

FIG 2 Frequency distribution of different pedigree lengths. 
TABLE 2 Possible cases of mutation

\begin{tabular}{|c|c|c|c|c|c|}
\hline Author & Legitimacy & Medical histories of relatives ' $P$ r & 'Probability' & Other details & Comments \\
\hline \multicolumn{6}{|l|}{ Bell20 quotes } \\
\hline $\begin{array}{r}\text { Geratovitsch } \\
\text { (1927) and }\end{array}$ & No & $\begin{array}{l}\text { Choreic offspring; parents } \\
\text { died healthy, } 80,73\end{array}$ & 0.01 & $\begin{array}{l}\text { Bell reports on } 151 \text { pedigrees, } P \\
\text { including } 991 \text { cases }\end{array}$ & $\begin{array}{l}\text { Plausible cases, but legitimacy } \\
\text { unproven and the pedigrees } \\
\text { are rather old }\end{array}$ \\
\hline $\begin{array}{r}\text { Smith (1898) } \\
\text { and }\end{array}$ & No & $\begin{array}{l}\text { Choreic offspring; parents } \\
\text { died healthy, } 93,87\end{array}$ & 0.001 & & \\
\hline Seip (1928) & No & $\begin{array}{l}\text { Choreic offspring; parents } \\
\text { died healthy, } 79,88 \text {; two } \\
\text { healthy sibs }\end{array}$ & & & \\
\hline Haugerud21 & Yes & $\begin{array}{l}\text { Parents healthy, } 64,62 ; \\
\text { grandparents died healthy, } \\
\text { maternal } 54,52, \text { paternal } \\
69,72 \text {. No trace in earlier } \\
\text { generations or parental sibs. } \\
\text { Pair of sibs affected }\end{array}$ & 0.07 & $\begin{array}{l}\text { Not from a survey; no } \\
\text { affected offspring. } \\
\text { Haugerud assumes a germ- } \\
\text { line mutation in one parent } \\
\text { to explain the observations }\end{array}$ & $\begin{array}{l}\text { Improbable, but could be a case } \\
\text { of phenocopy, as sibs share a } \\
\text { common environment }\end{array}$ \\
\hline Lyon ${ }^{1}$ & No & $\begin{array}{l}\text { Father died healthy, } 84 \text {. } \\
\text { Mother suffered ' } 12 \text { year } \\
\text { invalidity' of unspecified } \\
\text { nature }\end{array}$ & 一 & $\begin{array}{l}\text { No affected offspring. } \\
\text { Survey included } 28 \text { other } \\
\text { cases in a small population. } \\
\text { Lyon used this as an } \\
\text { example of 'non-hereditary } \\
\text { chorea' }\end{array}$ & $\begin{array}{l}\text { Unlikely, mother might have } \\
\text { been sufferer anyway }\end{array}$ \\
\hline $\begin{array}{l}\text { Minski and } \\
\text { Guttmann22 }\end{array}$ & No & $\begin{array}{l}\text { Parents died healthy, } 57 \text {, } \\
55 ; \text { psychoses in other } \\
\text { relatives }\end{array}$ & $0 \cdot 17$ & $\begin{array}{l}\text { Survey included } 140 \text { cases } \\
\text { in } 34 \text { families; diagnosis } \\
\text { explicitly doubtful }\end{array}$ & Improbable \\
\hline Pleydell23 & No & $\begin{array}{l}\text { Parents died healthy, } 70,71 \text {; } \\
7 \text { sibs and } 6 \text { parental sibs } \\
\text { also healthy at time of } \\
\text { report }\end{array}$ & 0.01 & $\begin{array}{l}\text { Oliver } 27 \text { expands the survey } \\
\text { to include } 18 \text { families, } 13 \\
\text { live cases (the putative } \\
\text { mutant was dead) }\end{array}$ & $\begin{array}{l}\text { Plausible but legitimacy } \\
\text { unproven }\end{array}$ \\
\hline Reed and Neel11 & No & $\begin{array}{l}\text { Parents healthy at } 65,65 ; 4 \\
\text { normal sibs; no kin reported } \\
\text { by family }\end{array}$ & 0.04 & $\begin{array}{l}\text { Reed and Neel report } 6 \\
\text { other possible cases, but in } \\
\text { these one or both parents } \\
\text { died young. Survey includes } \\
196 \text { lineages, } 231 \text { live } \\
\text { members at survey date }\end{array}$ & $\begin{array}{l}\text { Possible; Reed and Neel point } \\
\text { out that the length of their } \\
\text { series is enough to expect a } \\
\text { few cases like this. Heredity } \\
\text { unproven }\end{array}$ \\
\hline $\begin{array}{l}\text { Stevens and } \\
\text { Parsonage }^{24}\end{array}$ & No & $\begin{array}{l}\text { Parents died healthy, } 86,86 ; \\
\text { also } 7 \text { sibs died healthy; } 3 \\
\text { grandparents known to have } \\
\text { died healthy }\end{array}$ & 0.001 & $\begin{array}{l}114 \text { lineages included in } \\
\text { survey, } 133 \text { members alive } \\
\text { at survey }\end{array}$ & $\begin{array}{l}\text { Plausible but legitimacy } \\
\text { unproven }\end{array}$ \\
\hline
\end{tabular}

Probability is calculated as explained in the legend to fig 1.

TABLE 3 Survey data on incidence of sporadic cases

\begin{tabular}{|c|c|c|c|c|c|}
\hline Author (i) & Total live cases & Prevalence $\left(/ 10^{-6}\right)$ & Total families & Sporadics & Criteria including sporadics (ii) \\
\hline Bolt 26 & 154 & 52 & Unavailable (73) (iii) & 4 & $\mathbf{a}$ \\
\hline Caro $^{2}$ & 54 & 92 & 35 & 0 & \\
\hline Hayden et al $^{7}$ & 153 & 22 & Unavailable (72) (iii) & 8 & $\mathbf{b}$ \\
\hline Mattsson 19 & 362 & 47 & 110 & 9 & $\mathbf{a}$ \\
\hline Oliver 27 & 27 & 63 & 18 & 0 & \\
\hline Reed and Neel11 & 231 & 40 & 196 & 7 & $\mathbf{b}$ \\
\hline Shokeir ${ }^{18}$ & 162 & 84 & 58 & 5 & b \\
\hline Stevens 6 & 133 & 42 & Unavailable (63) (iii) & 0 & \\
\hline Wallaces & 111 & 63 & 46 & 1 & See table 2 \\
\hline Wendt and Drohm ${ }^{3}$ & 1032 & 22 & Unavailable (489) (iii) & 0 & c \\
\hline
\end{tabular}

Notes

(i) Surveys providing no useful information on the occurrence of sporadic cases have been excluded. References are exhaustively listed in Kurtzke $e$ t $a^{28}$ up to that date. The prevalence figures above are representative of those found in North European derived populations. Prevalence seems to be much lower in Japanese and Negro populations.

(ii) Criteria for including sporadic cases vary.

(a) Both parents healthy to older than 60; otherwise classic picture; no other familial evidence.

(b) Both parents died healthy at any age; otherwise classic picture; no other familial evidence.

(c) Wendt and Drohm ${ }^{3}$ state "... nicht einen Fall gibt, den wir mit Sicherheit als Neumutation ansprechen könnten". Their criteria were thus a demonstrated new mutant.

(iii) Figures in brackets are estimated numbers of families using the overall mean ratio of live cases to families from surveys where the data are available. The conclusions in the text are unaltered even if the maximum ratio is used instead of the mean. 
Here it is worth commenting on a procedure of Wallace $^{13}$ and Shokeir. ${ }^{18}$ They give tables showing the frequency distribution of different pedigree lengths. These have the general shape of fig 2 . Both authors suggest correction of the curve to obtain the true number of sufferers, as shown by the dotted line. This technique, which obviously considerably raises the number of 'sporadic' cases, among whom phenocopies and mutations are to be sought, is incorrect for a number of reasons. The curve in fig 2 is the product of two curves describing (1) the true distribution of lengths of choreic pedigrees, given perfect knowledge, and (2) the ease with which information can be gathered about a particular generation. (1) is determined by the detailed pattern of selection in every generation. This distribution could have almost any shape. In any case, it can be seen by examining published pedigrees that the pattern of fig 2 will be almost completely determined by factor (2). For example, among the pedigrees in Caro, ${ }^{25}$ all peter out through lack of information rather than definite knowledge of the origin of the disease through mutation. If Shokeir ${ }^{18}$ or Wallace ${ }^{13}$ had been more successful in tracing their pedigrees back to a mutational event, they would surely have reported the fact. Given this state of affairs, extrapolation from fig 2 as shown is completely unjustified, since the theoretical shape of the curve is unknown.

Table 3 lists surveys which are recent and reasonably extensive, and in which ascertainment was more or less as exhaustive as possible. Although these surveys refer to different times, they also refer to different places and estimates derived from them are therefore independent. Provided that the character and prevalence of Huntington's chorea is not changing rapidly, and that ascertainment efficiencies do not follow grossly different patterns in the different studies, the data from these studies may legitimately be averaged. The information these surveys collectively yield as to the proportion of sporadic Huntington's chorea cases will now be considered.

The maximum conceivable rate, admitting all cases in which the parents were known to be healthy until their deaths, or at the time of the survey, is $34 / 1387 \approx 2 \%$ on the basis of the total number of sufferers, or $34 / 671 \approx 5 \%$ using the total number of families. This derives from all surveys shown in table 3 except that of Wendt and Drohm ${ }^{3}$ (see note (c) in table 3). Criteria for defining sporadic cases vary slightly between reports, (see note in table 3), but this is not very important for these rough and generous estimates. Since none of these surveys regularly checked legitimacy, at least some of these cases are almost certain to arise via illegitimacy.
As there is a probability of 5 to $10 \%$ that onset of the disease will occur after the age of 60 , a proportion of such apparent sporadics is in any case to be expected. (There are other sources of information than the parents' health that can shed light on whether the disease was inherited or not. This accounts for the proportion of sporadics observed being rather smaller than the probability of late onset.) Turning from apparent sporadics to likely mutations, we can include all surveys in which mutation is mentioned and would therefore have been reported if it had been seen. The most likely mutation is that of Wallace. ${ }^{5}$ Stevens' subject ${ }^{6}$ could have been illegitimate and was, in any case, dead at the time of his prevalence study. Using the reports in table 3 we obtain a frequency of mutation among sufferers of $1 / 2419 \approx 0.04 \%$. In making this calculation we have subtracted from the total those cases in which a definite family history was not available. Considering, instead, numbers of families, the rate is $1 / 1160 \approx$ $0.1 \%$ with the same correction.

To sum up: apparent sporadics appear at a rate of 1 to $5 \%$. These fall into four classes as follows. Firstly, if family data are restricted, the affected parent may have died before showing symptoms. Secondly, the affected person may be illegitimate. Thirdly, there may exist phenocopies of the disease, or recessive genes giving the same phenotype. Finally, there are the true mutants, probably making up less than a tenth of the total.

For comparison purposes, an order of magnitude estimate of the absolute mutation rate may be of interest. Suppose the population is in a steady state. Then, if the average lifespan is 70 years, about $1 / 70$ or $1.4 \times 10^{-2}$ must be born each year. If the prevalence of Huntington's chorea is 50 to $100 \times 10^{-6}$ (see table 1), with a 15-year interval on average between onset and death, and mean onset at about the age of $40,{ }^{4}$ the incidence must be 3 to $7 \times 10^{-6}$. Then, using the higher incidence figure, choreic births form about $7 \times 10^{-6} / 1.4 \times 10^{-2}=5 \times 10^{-4}$ of all births. If 1 in 500 of these are new mutants, the mutation rate is about $\frac{1}{2} \times 10^{-6}$. If 1 in 1000 are new mutants and we take the lower incidence figure, the rate is nearer $10^{-7}$. These figures are on the low side but broadly speaking comparable with previous estimates (see table 1).

\section{Comparative data}

Stephenson and $\mathrm{Kerr}^{29}$ considered the available evidence on sex linked mutations in man, concluding that the average mutation rate at a given locus was likely to be substantially less than $10^{-6}$ per gamete, with considerable variation above and below this figure. The range of mutation rates suggested above 
for the Huntington's chorea locus fits this picture, which is also in general agreement with data from mice and Drosophila (see, for example, Dobzhansky ${ }^{30}$ ); but in any species the range of rates is so wide that it would be very surprising to find substantial disagreement. Any estimate between $10^{-9}$ and $10^{-5}$ would be reasonable.

\section{Conclusions}

Our fundamental belief is that it is wrong to tell the relatives of a patient suffering from a remarkably unpleasant, slow, progressive neurological disease, for which medical science can do virtually nothing, that they run a risk of also developing the disease, unless it is proven that they do so. The proportion of cases in which this question arises is, of course, irrelevant to this position. We believe that this review shows two things. Firstly, the number of cases in which a family history is genuinely negative is smaller than commonly believed; we have given reasons why this may be so. Secondly, the mutation rate to Huntington's chorea is very small in proportion to the total number of cases. Lastly, we wish to reiterate our belief that the label attached to patients who seem to suffer from a Huntington's chorea-like syndrome, but in whom the heritable nature of the disease is not proven, should not be Huntington's chorea but a neutral label.

\section{References}

1 Lyon RL. Huntington's chorea in the Moray Firth area. Br Med J 1962;i:1308.

2 Caro AJ. The prevalence of Huntington's chorea in an area of East Anglia. J R Coll Gen Pract 1977;27:41-5.

3 Wendt GG, Drohm D. Huntington's chorea. A population genetic study (Die Huntingtonsche Chorea-Eine Populationsgenetische Studie). In: Humangenetik: advances in human genetics. Stuttgart: Theime $1972 ; 4: 1-121$.

4 Bruyn GW. Huntington's chorea. Historial, clinical and laboratory synopsis. In: Vinken PJ, Bruyn GW, eds. Handbook of clinical neurology. Vol 6. Amsterdam: North Holland, 1968:298-378.

5 Wallace DC. Huntington's chorea in Queensland. A not uncommon disease. Med J Aust 1972; ii:299-307.

6 Stevens DL. Heterozygote frequency for Huntington's chorea. In: Barbeau A, Chase TN, Paulson GW, eds. Advances in neurology. Vol I. Huntington's chorea 18721972. New York: Raven Press, 1973:191-8.

7 Hayden MR, Macgregor JM, Beighton PM. The prevalence of Huntington's chorea in South Africa. $S A f r$ Med J 1980;58:193-6.

8 Haldane JBS. The formal genetics of man. Proc $R$ Soc Lond $[$ Biol $] 1948 ; 135: 147-70$.
9 Charlesworth B, Charlesworth D. Measurement of fitness and mutation rate in human populations. Ann Hum Genet $1973 ; 37: 175$.

10 Vogel F, Rathenberg R. Spontaneous mutation in man. Adv Hum Genet 1975;5:223-318.

11 Reed JE, Neel JV. Huntington's chorea in Michigan. 2. Selection and mutation. Am J Hum Genet 1959;11:107-36.

12 Yokoyama S, Templeton A. The effect of social selection on the population dynamics of Huntington's disease. Ann Hum Genet 1980;43:413-9.

13 Wallace DC. Social effect of Huntington's chorea on reproductive fitness. Ann Hum Genet 1976;39:375-9.

14 Kishimoto K, Nakamura M, Stokawa Y. On population genetics of Huntington's chorea in Japan. Ann Rep Res Inst Env Med Nagoya 1957;6:102-9.

15 Marx RN. Huntington's chorea in Minnesota. $A d v$ Neurol 1973;1:237-43.

16 Pearson JS, Petersen MC, Lazarte JA, Blodgett ME, Kley IB. An educational approach to the social problem of Huntington's chorea. Proc Mayo Clin 1955;30:349.

17 Panse F. Die Erbchorea; Eine Klinisch-genetische Studie. Leipzig: Thieme, 1942.

18 Shokeir MHK. Investigations on Huntington's disease in the Canadian Prairies. I. Prevalence. Clin Genet 1975; 7:345-8.

19 Mattsson B. Huntington's chorea in Sweden. 1. Prevalence and genetic data. Acta Psychiatr Scand 1974;255: 211-20.

20 Bell J. Huntington's chorea. In: The treasury of human inheritance. Vol 4, part 1. London: Cambridge University Press, 1934.

21 Haugerud S. Chronic progressive chorea in two sisters without demonstrable heredity. Schweiz Med Wochenschr $1968 ; 98: 2016$.

22 Minski L, Guttmann E. Huntington's chorea. A study of thirty four families. J Ment Sci $1938 ; 84: 21-96$.

23 Pleydell MJ. Huntington's chorea in Northamptonshire. Br Med J 1954 ;i:1121-8.

24 Stevens D, Parsonage M. Mutation in Huntington's chorea. J Neurol Neurosurg Psychiatry 1969;32:140.

25 Caro AJ. A genetic problem in East Anglia: Huntington's chorea. PhD thesis, University of East Anglia, 1977.

26 Bolt JMW. Huntington's chorea in the west of Scotland. Br J Psychiatry 1970;116:259.

27 Oliver JE. Huntington's chorea in Northamptonshire. $\mathrm{Br}$ J Psychiatry 1970;116:241-53.

28 Kurtzke JF, Anderson VE, Beebe GW, et al. Report of the work group on epidemiology, biostatistics and population genetics. In: Report: Commission for the control of Huntington's disease and its consequences. Vol III, part 1. Work Group Reports, Research. DHEW Pub No (NIH) 78-1503. Washington DC: US Government Printing Office, 1977:1-133, 1-236.

29 Stevenson AC, Kerr CB. On the distribution of frequencies of mutation to genes in determining harmful traits in man. Mutat Res 1967;4:339-52.

30 Dobzhansky T. Genetics of evolutionary process. New York: Columbia University Press, 1970.

Requests for reprints to Dr Adrian Caro, Theatre Royal Surgery, Theatre Street, Dereham, Norfolk NR19 2EN. 